\title{
Resection of recurrent hepatocellular carcinoma with thrombi in the inferior vena cava, right atrium, and phrenic vein: a report of three cases
}

\author{
Koichi Tomita', Motohide Shimazu², Kiminori Takano ${ }^{3}$, Takahiro Gunji', Yosuke Ozawa', Toru Sano',
} Naokazu Chiba', Yuta Abe ${ }^{4}$ and Shigeyuki Kawachi ${ }^{1 *}$ (D)

\begin{abstract}
Background: Prognosis for patients with advanced hepatocellular carcinoma with a tumor thrombus in the inferior vena cava or right atrium is extremely poor due to cancer progression, pulmonary embolism, and congestion of the circulatory system caused by right heart failure. Surgical resection of the tumor thrombi may potentially yield better results than non-surgical treatments through prevention of sudden death. However, the benefits of surgical resection in patients with hepatocellular carcinoma and a tumor thrombus extending to the inferior vena cava, right atrium, and potentially in the phrenic vein are unclear. Here, we report three such cases.

Case presentation: Of the total 136 patients who underwent hepatectomies for hepatocellular carcinoma in our institution, three patients with prior hepatectomies and recurrent hepatocellular carcinoma had tumor thrombi in the inferior vena cava, right atrium, and phrenic vein. Surgical resections were performed, as there was a possibility of sudden death, despite the risk of leaving residual tumor. For all patients, we performed resection of the tumor thrombi in the inferior vena cava and right atrium and combined diaphragm resection. Surgical resection was performed using the total hepatic vascular exclusion technique in all cases. Additional passive veno-venous bypass was also performed in two cases, in which complete tumor resections could not be achieved. The microscopic surgical margins of the combined resected diaphragms were positive in all cases. Progression-free survival was 20.2, 3.8, and 9.5 months for case 1, 2, and 3, respectively. The respective overall postoperative survival was 98.0, 38.9, and 30.9 months. The patients died due to liver cirrhosis, acute heart failure, and hepatocellular carcinoma, respectively. Sudden death did not occur for any of the patients.

Conclusion: Surgical resections may extend prognosis for patients with recurrent hepatocellular carcinoma with tumor thrombi in the inferior vena cava, right atrium, and phrenic vein, although the indications should be considered carefully.
\end{abstract}

Keywords: Hepatocellular carcinoma, Inferior vena cava, Phrenic vein, Right atrium, Tumor thrombus

\footnotetext{
* Correspondence: skawachi@tokyo-med.ac.jp

'Department of Digestive and Transplantation Surgery, Tokyo Medical

University Hachioji Medical Center, 1163 Tatemachi, Hachioji-shi, Tokyo

193-0998, Japan

Full list of author information is available at the end of the article
}

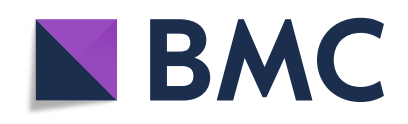

(- The Author(s). 2020 Open Access This article is licensed under a Creative Commons Attribution 4.0 International License, which permits use, sharing, adaptation, distribution and reproduction in any medium or format, as long as you give appropriate credit to the original author(s) and the source, provide a link to the Creative Commons licence, and indicate if changes were made. The images or other third party material in this article are included in the article's Creative Commons licence, unless indicated otherwise in a credit line to the material. If material is not included in the article's Creative Commons licence and your intended use is not permitted by statutory regulation or exceeds the permitted use, you will need to obtain permission directly from the copyright holder. To view a copy of this licence, visit http://creativecommons.org/licenses/by/4.0/. The Creative Commons Public Domain Dedication waiver (http://creativecommons.org/publicdomain/zero/1.0/) applies to the data made available in this article, unless otherwise stated in a credit line to the data. 


\section{Background}

The prognosis for patients with advanced hepatocellular carcinoma (HCC) with a tumor thrombus in the inferior vena cava (IVC) or right atrium (RA), defined as Vv3 by the American Joint Committee on Cancer and the Union for International Cancer Control [1], is extremely poor due to cancer progression, pulmonary embolism-related sudden death [2], and congestion of the circulatory system caused by right heart failure [3].

According to the European Association for the Study of the Liver guidelines, Vv3 cases are classified as Barcelona-Clinic Liver Cancer Stage C, and their recommended treatment is "systemic therapy" [4]. The American Association for the Study of Liver Disease also suggests the same treatment [5]. Conversely, surgical resections of the tumor thrombi may potentially yield better results than non-surgical treatments through prevention of sudden death, with some patients achieving long-term survival [6].

A tumor thrombus may appear not only in the IVC and RA, but also in the phrenic vein. The effect of surgical resections in these cases is unclear. Herein, we describe three patients with recurrent $\mathrm{HCC}$ and a tumor thrombus in the IVC, RA, and phrenic vein who underwent surgical resection of the tumor thrombus combined with diaphragm resection. We aimed to determine whether performing surgical resections for this tumor type would improve patient prognosis.

\section{Case presentations \\ Patients}

A total of 136 patients underwent hepatectomies for HCC at our center between November 2006 and December 2019. Of these patients, tumors extending to the IVC were diagnosed in four. We performed surgical resections for these patients, as there was a possibility of sudden death due to pulmonary embolisms or cardiac failure caused by the tumor thrombus, although the possibility of leaving residual tumor remained.

Three of the four patients had recurrent HCC and are presented below. According to dynamic-enhanced computed tomography imaging or magnetic resonance imaging, regions of low density or low intensity were recognized as tumor thrombi in the IVC, RA, and phrenic vein. The patient features are listed in Table 1.

This study was approved by the institutional review board of Tokyo Medical University (T2019-0256). Written informed consent was obtained from all patients.

\section{Case 1}

The patient was a 69-year-old man with a history of heavy alcohol use. Transarterial chemoembolization (TACE) had been performed twice for HCC at another hospital, 7 years prior to our surgery. Additionally, a left hepatectomy was performed 1 year before our surgery. After the hepatectomy, recurrent $\mathrm{HCC}$ was recognized in segment $(\mathrm{S})$ 8, and radiofrequency ablation was performed. Subsequently, a tumor thrombus in the IVC, RA, and phrenic vein was detected (Fig. 1). The thrombus was close to the stump of the remnant liver and left hepatic vein, though not detectable inside the remnant liver.

\section{Case 2}

The patient was a 40-year-old woman with HCC of unknown etiology. Lateral sectionectomy had been performed for HCC 11 years before our surgery at another hospital. Afterwards, TACE was repeatedly performed for HCC of S7 and S8. However, a tumor thrombus was recognized near the S7 tumor (Fig. 2).

\section{Case 3}

The patient was a 75-year-old woman with chronic hepatitis $\mathrm{C}$ viral infection. Repeated TACE, percutaneous ethanol injection therapy, and radiofrequency ablation had been performed for multiple HCCs of both lobes during 8 years before our surgery. After these treatments, a low-density area was recognized under the diaphragm with a tumor thrombus (Fig. 3).

\section{Surgical procedure}

After obtaining informed consent, surgical resection was selected for these three patients for the prevention of sudden death due to tumor thrombosis. Although there was a chance of complete tumor resection, this outcome was expected to be difficult to achieve. Therefore, the possibility of the surgery being non-curative was fully explained to the patients before surgery.

Surgical resection of the tumor thrombus extending from the IVC to the RA was performed using the total hepatic vascular exclusion (THVE) technique without cardiopulmonary bypass. The vasculature around the liver, including the hepatoduodenal ligament, infrahepatic IVC, and suprahepatic IVC, were encircled and excluded during the reconstruction of the IVC. Further, draining of the left adrenal and lumbar veins to the IVC was divided when possible. Intraoperatively, the RA was clamped instead of the suprahepatic IVC. Intraabdominal and transesophageal ultrasound sonography were used during surgery to avoid damaging the tumor thrombus and tricuspid valve. RA clamping was performed beneath the right coronary artery and coronary sinus.

In cases 2 and 3, the blood pressure was unstable during THVE due to clamping of the IVC, and an additional passive veno-venous bypass with a heparinized catheter was used. The portal flow was passively shunted from the inferior mesenteric to the left axial vein to prevent 
Table 1 Course of the three patients with tumor thrombi in the IVC, RA, and phrenic vein

\begin{tabular}{|c|c|c|c|c|}
\hline Case no. & & 1 & 2 & 3 \\
\hline Age, years & & 69 & 40 & 75 \\
\hline Sex & & Male & Female & Female \\
\hline \multirow[t]{5}{*}{ Preoperative information } & Etiology & Alcoholic & Unknown & $\mathrm{HCV}$ \\
\hline & Past treatment & $\begin{array}{l}\text { 1. TACE (left lobe, S8) } \\
\text { 2. Left hepatectomy } \\
\text { 3. RFA (S8) }\end{array}$ & $\begin{array}{l}\text { 1. Lateral sectionectomy } \\
\text { 2. TACE }(S 7, S 8)\end{array}$ & $\begin{array}{l}\text { 1. TACE } \\
\text { 2. PEIT, RFA } \\
\text { 3. TACE, RFA }(S 7,8)\end{array}$ \\
\hline & Child-Pugh (score, grade) & $7, B$ & $5, A$ & $6, A$ \\
\hline & Tumor markers before surgery & $\begin{array}{l}\text { AFP } 912 \mathrm{ng} / \mathrm{mL} \\
\text { PIVKA-II } 294 \mathrm{U} / \mathrm{mL}\end{array}$ & $\begin{array}{l}\text { AFP } 15 \mathrm{ng} / \mathrm{mL} \\
\text { PIVKA-\|I } 25681 \mathrm{U} / \mathrm{mL}\end{array}$ & $\begin{array}{l}\text { AFP } 9521 \mathrm{ng} / \mathrm{mL} \\
\text { PIVKA-\| } 4476 \mathrm{U} / \mathrm{mL}\end{array}$ \\
\hline & Tumor location & IVC, RA, diaphragm & S7, IVC, RA, diaphragm & S7, IVC, RA, diaphragm \\
\hline \multirow[t]{6}{*}{ Operative findings } & Surgical procedure & $\begin{array}{l}\text { RA thrombectomy } \\
\text { Diaphragm resection }\end{array}$ & $\begin{array}{l}\text { RA thrombectomy } \\
\text { Diaphragm resection } \\
\text { Posterior sectionectomy }\end{array}$ & $\begin{array}{l}\text { RA thrombectomy } \\
\text { Diaphragm resection }\end{array}$ \\
\hline & Hepatectomy & - & + & - \\
\hline & Operation time & $9 \mathrm{~h} 2 \mathrm{~min}$ & $10 \mathrm{~h} 0 \mathrm{~min}$ & $8 \mathrm{~h} 15 \mathrm{~min}$ \\
\hline & THVE time, min & 26 & 21 & 25 \\
\hline & V-V bypass & - & + & + \\
\hline & Bleeding, $g$ & 2705 & 1080 & 4230 \\
\hline \multirow[t]{2}{*}{ Pathological findings } & Differentiation & Poor & Moderate & Poor \\
\hline & Surgical margin & +, diaphragm & +, diaphragm & +, diaphragm \\
\hline \multirow[t]{8}{*}{ Postoperative course } & Complication & Pleural effusion & Pleural effusion & $\begin{array}{l}\text { Respiratory failure } \\
\text { Pleural effusion }\end{array}$ \\
\hline & Postoperative stay, days & 42 & 14 & 43 \\
\hline & Tumor marker (ЗРОМ) & $\begin{array}{l}\text { AFP } 89 \mathrm{ng} / \mathrm{mL} \\
\text { PIVKA-II } 79 \mathrm{U} / \mathrm{mL}\end{array}$ & $\begin{array}{l}\text { AFP } 16 \mathrm{ng} / \mathrm{mL} \\
\text { PIVKA-II } 633 \mathrm{U} / \mathrm{mL}\end{array}$ & $\begin{array}{l}\text { AFP } 573 \mathrm{ng} / \mathrm{mL} \\
\text { PIVKA-II } 3021 \mathrm{U} / \mathrm{mL}\end{array}$ \\
\hline & CTx after surgery & Sorafenib & Sorafenib & Sorafenib \\
\hline & Recurrence & Parasternal site & Lung, bone & Remnant liver (S7) \\
\hline & PFS, months & 20.2 & 3.8 & 9.5 \\
\hline & Death & Liver cirrhosis & Acute heart failure & $\mathrm{HCC}$ \\
\hline & Postoperative survival, months & 98.0 & 38.9 & 30.9 \\
\hline
\end{tabular}

Abbreviations: IVC inferior vena cava, RA right atrium, HCV hepatitis C virus, TACE trans-catheter arterial chemoembolization, PEIT percutaneous ethanol injection therapy, RFA radiofrequency ablation, AFP alpha-fetoprotein, PIVKA-II protein-induced by vitamin $\mathrm{K}$ absence-Il, THVE total hepatic vascular exclusion, POM postoperative month, CTx chemotherapy, PFS progression free survival, HCC hepatocellular carcinoma

intestinal congestion. The IVC flow was also extracted from the right femoral vein and passively directed to the left axial vein with portal flow by a Y-shaped connector. During the veno-venous bypass, systemic heparinization or the use of a Bio-Pump was not necessary.

Bovine pericardium (Edwards Lifesciences ${ }^{\circ}$, Irvine, CA, USA) was used during the reconstruction of the RA and IVC wall defect (Fig. 4); when needed, it was also used for reconstruction of diaphragm defects.

\section{Operative findings}

In all three patients, the tumor thrombi of the IVA and RA were considered to have extended to the phrenic vein. Thrombectomies in the IVC and RA and combined diaphragm resections were performed. For case 2, a hepatic posterior sectionectomy was also performed for resection of the intrahepatic HCC. For case 1, macroscopic complete resection of the inferior phrenic vein with tumor thrombus was performed, although the microscopic surgical margin was proven to be positive. For case 2, the microscopic tumors extended broadly inside the diaphragm and could not be completely resected, although the diaphragm was resected to the extent possible. For case 3, the intrahepatic tumor mass was not capsulated, and a part of it could not be resected because it was close to the umbilical portion.

\section{Pathological findings}

The resected specimens of cases 1 and 3 are shown in Figs. 5 and 6, respectively (there were no available photographs for case 2). The tumors were not capsulized in all cases and were necrotic in cases 2 and 3 . 


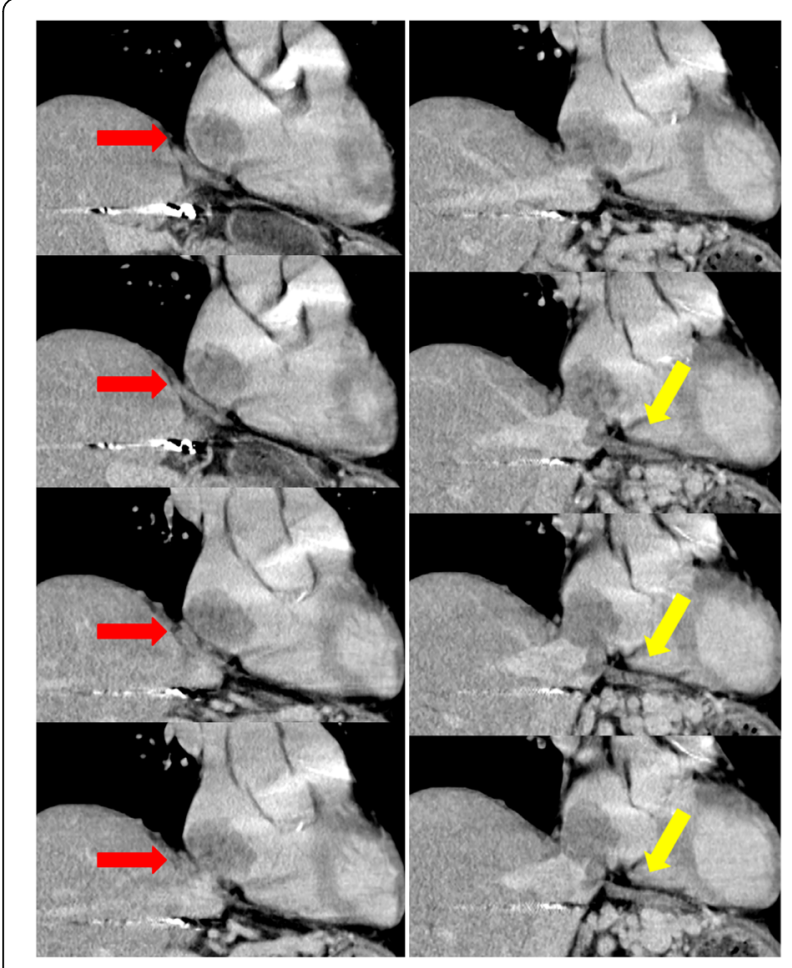

Fig. 1 Dynamic-enhanced computed tomography imaging of case 1 (reconstruction for the coronal axis). A tumor thrombus was detected in both the inferior vena cava (IVC) and right atrium (RA) (red arrow), with extension to the left phrenic vein (yellow arrow)

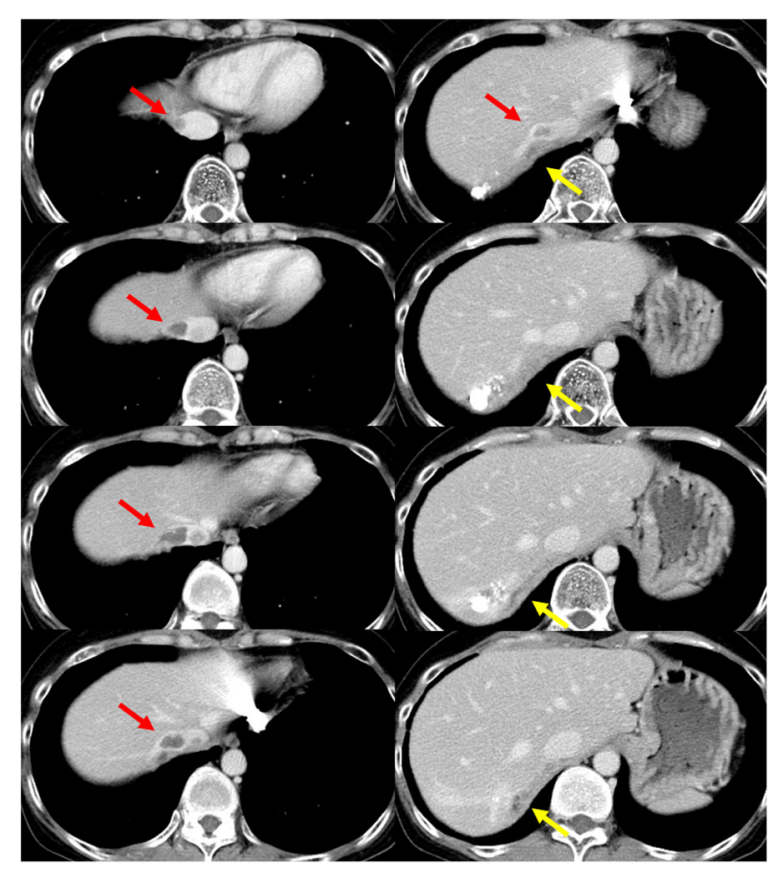

Fig. 2 Dynamic-enhanced computed tomography imaging of case 2. A tumor thrombus was detected in the right hepatic vein, inferior vena cava (IVC), and right atrium (RA; red arrow), as well as in the right phrenic vein (yellow arrow)

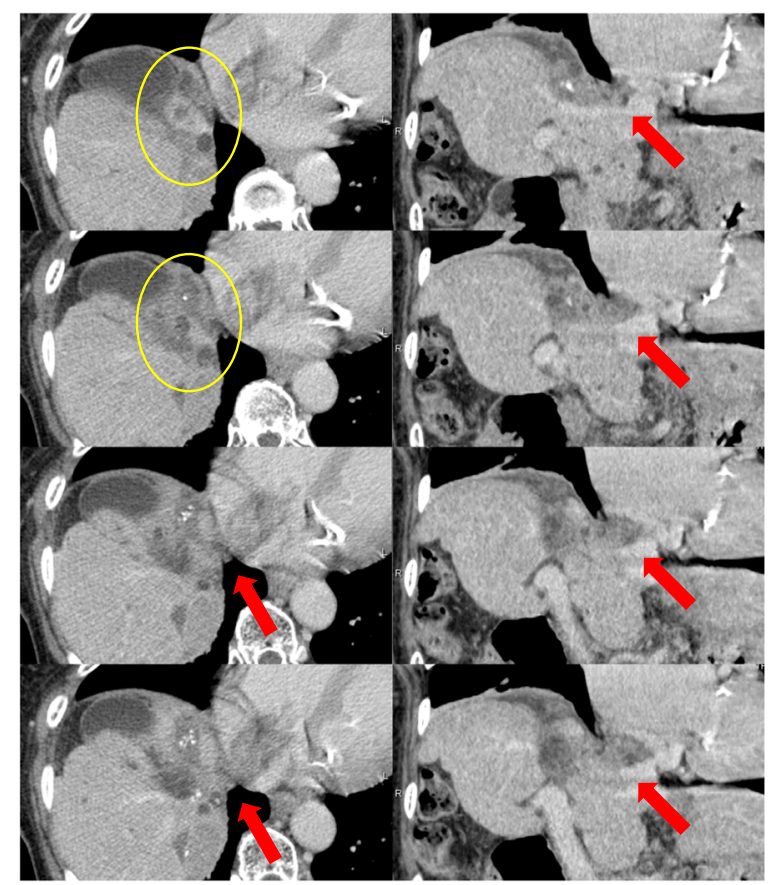

Fig. 3 Dynamic-enhanced computed tomography imaging of case 3. Tumor thrombus was detected in the right hepatic vein, inferior vena cava (IVC), and right atrium (RA; red arrow), as well as in the right phrenic vein (yellow circle). The left column shows the axial view, and the right column shows the coronal view

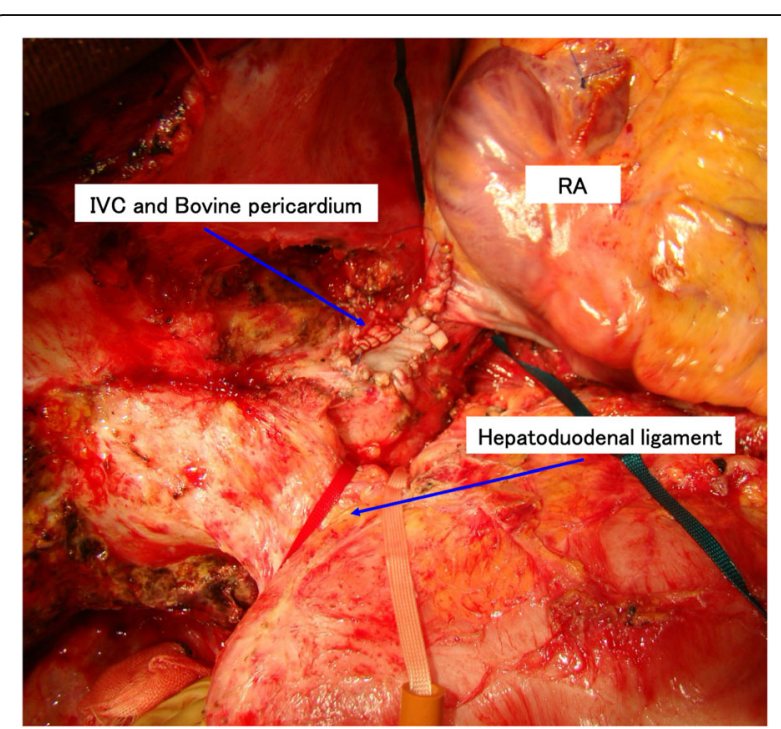

Fig. 4 Surgical view of case 1. View after resection of the tumor thrombus and reconstruction of the inferior vena cava (IVC) and right atrium (RA) wall defect, using bovine pericardium 


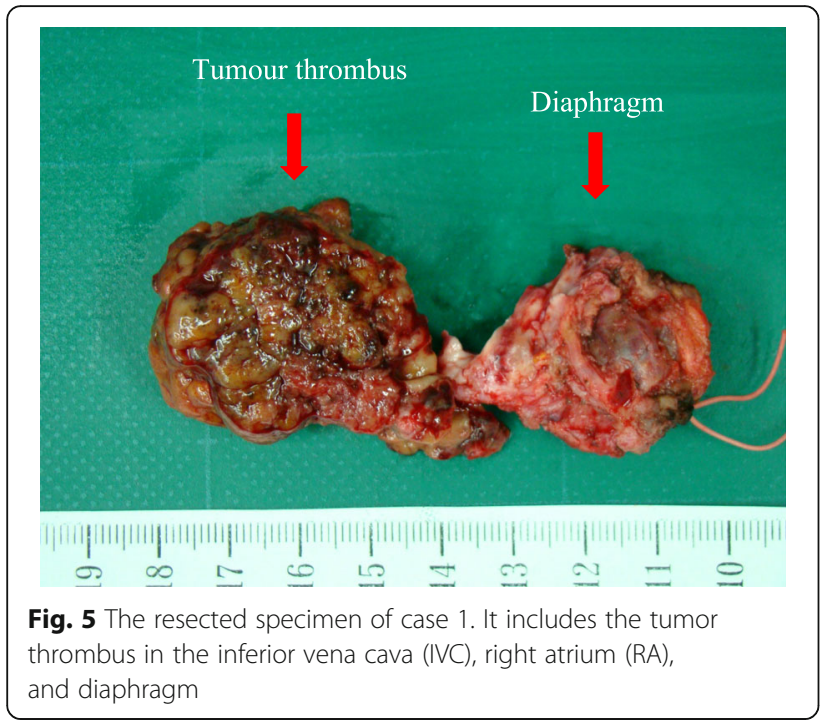

Furthermore, in all cases, tumor thrombi were recognized in the IVC and RA and inside the phrenic vein, where they had progressed extensively. Cases 1 and 3 had poorly differentiated HCCs, while case 2 had a moderately differentiated HCC. The microscopic surgical margins were positive in all three patients at the site of the resected diaphragm margins, whereas the tumor thrombi in the IVC and RA were totally resected.

\section{Postoperative course}

Pleural effusions were postoperatively recognized in all three patients, though disappeared through a conservative approach. Patients 1,2 , and 3 were discharged on postoperative days 42,14 , and 43 , respectively.

The postoperative levels of alfa-fetoprotein and protein induced by vitamin $\mathrm{K}$ absence-II tumor markers

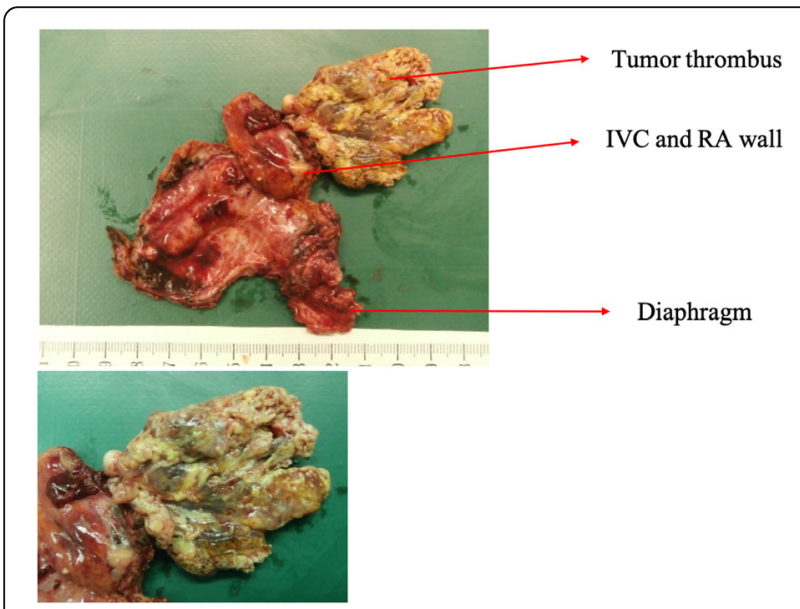

Fig. 6 The resected specimen from case 3. It includes the tumor thrombus, inferior vena cava (IVC), right atrium (RA) wall, and diaphragm decreased compared to the preoperative values in all three patients, although they remained outside their normal ranges.

All patients were postoperatively administered sorafenib to prevent tumor progression, although the tumors progressed 3.8 to 20.2 months postoperatively in all cases. In case 1, recurrence was suspected at the parasternal site, although it had remained unchanged after the radiation therapy. In cases 2 and 3, the recurrences were detected in the lung and bone and the residual intrahepatic HCC, respectively, although there were no recurrences of the IVC thrombi. The overall survival was 98.8 months for case 1 (died of liver cirrhosis), 38.9 months for case 2 (died of acute heart failure), and 30.9 months for case 3 (died of HCC).

\section{Discussion}

In this report, we presented the cases of three patients with recurrent HCCs and tumor thrombi in the IVC, $\mathrm{RA}$, and phrenic vein. Tumor resections, including the tumor thrombus and diaphragm, were performed for these patients. Their prognosis was better than that of common Vv3 cases, in which the tumor thrombus progresses via the major hepatic veins.

In general, an HCC tumor thrombus of either the IVC or RA is uncommon and may result in intrapulmonary dissemination and/or pulmonary embolisms [2]. Additionally, a tumor thrombus of the RA may obstruct the orifice of the tricuspid valve, resulting in sudden cardiac arrest [3]. The median survival time (MST) of Vv3 (tumor thrombus in the IVC) has been shown to be less than 6 months, with no patients surviving beyond 2 years [7].

Treatment of Vv3 cases includes TACE [8], chemotherapy [9], stereotactic body radiotherapy [10], particle radiotherapy [11], and surgical resection. When compared with non-surgical treatments, tumor resections that include a tumor thrombus in the IVC or RA may improve the prognosis of patients with $\mathrm{HCC}$ by preventing sudden death [12]. Based on a nationwide Japanese survey, Kokudo et al. reported a better MST after surgical resections than after non-surgical treatments in Vv3 cases $(1.48$ vs. 0.84 years, $P<0.001)[13]$.

Tumor thrombi may rarely appear in the phrenic vein, and in such cases, the effect of surgical resections, including combined diaphragm resections, is unclear and has not previously been reported. The three cases presented here indicate that patients with a tumor thrombus in the IVC, RA, and phrenic vein may have a better prognosis when treated with surgical resections including the diaphragm. The improved prognosis may be related to the presumed slow growth of the tumor thrombus in these cases. According to the preoperative images of our cases, the primary masses and thrombi were hypovascular, appeared to be fed by the inferior 
phrenic artery, and the number of the arteries was very small. Additionally, the postoperative pathological findings showed that the tumors were necrotic, especially inside the masses and thrombi. These findings may support the assertion that recurrent HCCs grow slowly and are less vascular. Surgical resections may be effective for these slow-growing tumors, as they may permit a relatively longer survival, even if the tumor recurs. Moreover, in our cases, the tumor thrombi extended inside the phrenic vein continuously from the IVC or diaphragm. This finding also supports the effectiveness of surgical resections.

When considering the mechanisms of tumor progression in our patients, there are several speculations. Because the tumor mass was not recognized outside the IVC in case 1 , it is possible that the tumor thrombus in the phrenic vein originated from a recurrence at the IVC wall. In previous reports, recurrent HCCs may have developed solitarily in the IVC [14] or in the heart [15]. It is also possible that the tumor thrombus had progressed from the intrahepatic or subphrenic tumor mass. Conversely, it might have extended to the diaphragm or subphrenic area.

The indication for surgical resections in these cases was difficult. In general, aggressive surgery for an HCC thrombus in the IVC is typically followed by early recurrence and subsequent difficulty in treatment of the recurrence site [16]. Other reports have indicated that surgical resection may be considered for the prevention of sudden death if distant metastasis and recurrence in the remnant liver are controlled [17]. In our cases, complete tumor resections could not be achieved, and the surgical margins were positive in all cases, especially in the combined resected diaphragm margins. However, we believe that surgical resection for the prevention of sudden death followed by intensive treatment, including chemotherapy and TACE, may improve patient prognosis. Additionally, the use of sorafenib as an adjuvant therapy might improve the prognosis in our cases, though the effectiveness of adjuvant therapies for hepatocellular resection has not been established.

There were possible postoperative complications related to the surgical procedure for these cases. Previous reports have observed pleural effusion, ascites [6], acute renal failure, and atrial fibrillation [16] as the postoperative complications. In the present study, pleural effusion was observed in all cases.

Finally, surgical resection of a tumor with a thrombus formation that has extended into the RA generally requires cardiopulmonary bypass [18]. Unfortunately, tumor resection under cardiopulmonary bypass is an invasive surgery with frequent postoperative complications. As indicated in this study, THVE is a useful procedure for tumor resections in the IVC [19-21]. If the systemic circulation is unstable or intestinal congestion has occurred, both passive veno-venous bypass from the infra-hepatic IVC and portal flow to the left axial vein can be performed simultaneously [22].

This study had some limitations. Only three cases were analyzed, making it difficult to conclude whether surgical resections are truly effective for recurrent HCCs with tumor thrombi in the IVC, RA, and phrenic vein. Therefore, further investigations will be needed to examine the usefulness of surgical resections in such cases.

\section{Conclusions}

Surgical resections for recurrent HCCs with tumor thrombi in the IVC, RA, and phrenic vein may improve patient prognosis, although the indications should be considered carefully.

\section{Abbreviations}

HCC: Hepatocellular carcinoma; IVC: Inferior vena cava; MST: Median survival time; RA: Right atrium; TACE: Transarterial chemoembolization; THVE: Total hepatic vascular exclusion

\section{Acknowledgements}

Not applicable

\section{Authors' contributions}

M Shimazu mainly performed surgical procedures. All authors contributed to the acquisition of data. K Tomita analyzed and interpreted the patient data. K Tomita and K Takano were major contributors in writing the manuscript. All authors read and approved the final manuscript.

\section{Funding}

There was no funding for this study.

Availability of data and materials

All data generated or analyzed during this study are included in this published article.

Ethics approval and consent to participate

This study was approved by the institutional review board of Tokyo Medical University (T2019-0256). Informed consent was obtained from all patients.

Consent for publication

Written informed consent was obtained from all patients.

Competing interests

The authors declare that they have no competing interests

\section{Author details}

${ }^{1}$ Department of Digestive and Transplantation Surgery, Tokyo Medical University Hachioji Medical Center, 1163 Tatemachi, Hachioji-shi, Tokyo 193-0998, Japan. ²Department of Surgery, Tama Kyuryo Hospital, 1491 Shimooyamada, Machida-shi, Tokyo 194-0297, Japan. ${ }^{3}$ Department of Surgery, Hiratsuka City Hospital, 1-19-1 Minamihara, Hiratsuka-shi, Kanagawa 254-0065, Japan. ${ }^{4}$ Department of Surgery, Keio University School of Medicine, 35 Shinanomachi, Shinjuku-ku, Tokyo 160-8582, Japan.

Received: 30 April 2020 Accepted: 12 June 2020

Published online: 22 June 2020

\section{References}

1. O'Sullivan B, Brierley J, Byrd D, Bosman F, Kehoe S, Kossary C, et al. The TNM classification of malignant tumors-towards common understanding and reasonable expectations. Lancet Oncol. 2017;18:849-51.

2. Papp E, Keszthelyi Z, Kalmar NK, Papp L, Weninger C, Tornoczky T, et al. Pulmonary embolization as primary manifestation of hepatocellular 
carcinoma with intracardiac penetration: a case report. World J Gastroenterol. 2005;11:2357-9.

3. Lazopoulos GL, Manns-Kantartzis M, Kantartzis MN. Severe right atrial obstruction due to cardiac extension of a hepatic carcinoma. Ann Thorac Surg. 2009;87:645.

4. European Association for the Study of the Liver. EASL clinical practice guidelines: management of hepatocellular carcinoma. J Hepatol. 2018;69: 182-236.

5. Marrero JA, Kulik LM, Sirlin CB, Zhu AX, Finn RS, Abecassis MM, et al. Diagnosis, staging, and management of hepatocellular carcinoma: 2018 practice guidance by the American association for the study of liver diseases. Hepatology. 2018;68:723-50.

6. Wang Y, Yuan L, Ge RL, Sun Y, Wei G. Survival benefit of surgical treatment for hepatocellular carcinoma with inferior vena cava/right atrium tumor thrombus: results of a retrospective cohort study. Ann Surg Oncol. 2013;20: 914-22.

7. Ikai I, Yamamoto Y, Yamamoto N, Terajima H, Hatano E, Shimahara Y, et al. Results of hepatic resection for hepatocellular carcinoma invading major portal and/or hepatic veins. Surg Oncol Clin N Am. 2003;12:65-75 ix.

8. Chern MC, Chuang VP, Cheng T, Lin ZH, Lin YM. Transcatheter arterial chemoembolization for advanced hepatocellular carcinoma with inferior vena cava and right atrial tumors. Cardiovasc Intervent Radiol. 2008;31:73544.

9. Liu J, Wang Y, Zhang D, Liu B, Ou Q. Comparison of survival and quality of life of hepatectomy and thrombectomy using total hepatic vascular exclusion and chemotherapy alone in patients with hepatocellular carcinoma and tumor thrombi in the inferior vena cava and hepatic vein. Eur J Gastroenterol Hepatol. 2012;24:186-94.

10. Xi M, Zhang L, Zhao L, Li QQ, Guo SP, Feng ZZ, et al. Effectiveness of stereotactic body radiotherapy for hepatocellular carcinoma with portal vein and/or inferior vena cava tumor thrombosis. PLoS One. 2013;8:e63864

11. Komatsu S, Kido M, Asari S, Toyama H, Ajiki T, Demizu Y, et al. Particle radiotherapy, a novel external radiation therapy, versus liver resection for hepatocellular carcinoma accompanied with inferior vena cava tumor thrombus: a matched-pair analysis. Surgery. 2017;162:1241-9.

12. Hemming AW, Reed Al, Langham MR, Fujita S, Howard RJ. Combined resection of the liver and inferior vena cava for hepatic malignancy. Ann Surg. 2004;239:712-9 discussion 719-21.

13. Kokudo T, Hasegawa K, Matsuyama Y, Takayama T, Izumi N, Kadoya M, et al. Liver resection for hepatocellular carcinoma associated with hepatic vein invasion: a Japanese nationwide survey. Hepatology. 2017;66:510-7.

14. Shimizu S, Yamazaki O, Horii K, Kanazawa A, Tamamori Y, Nakazawa K, et al. Two cases of hepatocellular carcinoma with metastasis to the inferior vena cava. Kanzo. 2006;47:223-8 Available at https://www.jstage.jst.go.jp/article/ kanzo/47/4/47_4_223/_pdf/-char/ja.

15. Kawakami M, Koda M, Mandai M, Hosho K, Murawaki Y, Oda W, et al. Isolated metastases of hepatocellular carcinoma in the right atrium: case report and review of the literature. Oncol Lett. 2013;5:1505-8.

16. Wakayama K, Kamiyama T, Yokoo H, Kakisaka T, Kamachi H, Tsuruga Y, et al. Surgical management of hepatocellular carcinoma with tumor thrombi in the inferior vena cava or right atrium. World J Surg Oncol. 2013;11:259.

17. Inoue $Y$, Hayashi M, Katsumata T, Shibayama Y, Tanigawa N. Hepatocellula carcinoma with right atrial tumor thrombus: report of a case. Surg Today. 2011;41:1122-9.

18. Wu CC, Hseih S, Ho WM, Tang JS, Liu TJ, P'eng FK. Surgical treatment for recurrent hepatocellular carcinoma with tumor thrombi in right atrium: using cardiopulmonary bypass and deep hypothermic circulatory arrest. J Surg Oncol. 2000;74:227-31.

19. Shivathirthan N, Shimoda M, Kosuge T, Kato M, Kijima H, Sawada T, et al. Recurrent hepatocellular carcinoma with tumor thrombus in right atrium report of a successful liver resection with tumor thrombectomy using total hepatic vascular exclusion without concomitant cardiopulmonary bypass. Hepatogastroenterology. 2012;59:872-4.

20. Ohwada S, Takahashi T, Tsutsumi H, Kawate S, Ohki S, Hamada K. Hepatocellular carcinoma with a tumor thrombus extending to the tricuspid valve: report of a successful en bloc resection. Hepatogastroenterology. 2008:55:903-6.

21. Uemura M, Sasaki Y, Yamada T, Equchi H, Ohigashi H, Doki Y, et al. Surgery for hepatocellular carcinoma with tumor thrombus extending into the right atrium: report of a successful resection without the use of cardiopulmonary bypass. Hepatogastroenterology. 2004;51:1259-62.
22. Itoh A, Sadamori H, Yabushita K, Monden K, Tatsukawa M, Hioki M, et al. Advanced hepatocellular carcinoma with hepatic vein tumor thrombosis and renal dysfunction after hepatic arterial infusion chemotherapy effectively treated by liver resection with active veno-venous bypass: report of a case. BMC Cancer. 2016;16:705

\section{Publisher's Note}

Springer Nature remains neutral with regard to jurisdictional claims in published maps and institutional affiliations.
Ready to submit your research? Choose BMC and benefit from:

- fast, convenient online submission

- thorough peer review by experienced researchers in your field

- rapid publication on acceptance

- support for research data, including large and complex data types

- gold Open Access which fosters wider collaboration and increased citations

- maximum visibility for your research: over $100 \mathrm{M}$ website views per year

At BMC, research is always in progress.

Learn more biomedcentral.com/submissions 